\title{
Analysis of Rainfall Trends and Its Relationship with SST Signals in the Lake Tana Basin, Ethiopia
}

\author{
Tesfay Mekonnen Weldegerima ${ }^{D},{ }^{1}$ Tadesse Terefe Zeleke, ${ }^{2}$ Belay Simane Birhanu, ${ }^{3}$ \\ Benjamin Frederick Zaitchik, ${ }^{4}$ and Zewdu Alamineh Fetene $\mathbb{D}^{1}$ \\ ${ }^{1}$ Atmospheric Physics, Bahir Dar University, P.O. Box 79, Bahir Dar, Ethiopia \\ ${ }^{2}$ Institute of Geophysics, Space Science and Astronomy (IGSSA), Addis Ababa University, Addis Ababa, Ethiopia \\ ${ }^{3}$ College of Development Studies, Addis Ababa University, Addis Ababa, Ethiopia \\ ${ }^{4}$ Department of Earth and Planetary Sciences, Johns Hopkins University, Baltimore, MD 21218, USA
}

Correspondence should be addressed to Tesfay Mekonnen Weldegerima; tesfaym270@gmail.com

Received 12 December 2017; Revised 9 March 2018; Accepted 16 April 2018; Published 16 May 2018

Academic Editor: Francesco Viola

Copyright ( $\odot 2018$ Tesfay Mekonnen Weldegerima et al. This is an open access article distributed under the Creative Commons Attribution License, which permits unrestricted use, distribution, and reproduction in any medium, provided the original work is properly cited.

\begin{abstract}
The impacts of climate change and climate variability on human life have led the scientific community to monitor the behavior of weather and climate variables at different spatial and temporal scales. This paper explores seasonal and annual trends of rainfall in the Lake Tana basin (LTB) and their teleconnections with global sea surface temperatures (SSTs) over the period between 1979 and 2015. The nonparametric Mann-Kendall test and Sen's slope estimate are applied to the rainfall data collected from the National Meteorology Agency (NMA) of Ethiopia for detecting and estimating rainfall trends. Additionally, Pearson's correlation coefficient method is used to determine the effect of SST variations on rainfall. The assessment of rainfall trends indicates that the amount of annual rainfall in the Lake Tana basin is increasing, but the rate of increase is not statistically significant. Seasonal analysis reveals that the smallest amount of rainfall occurs in the Bega season, and this season is getting drier with time. However, the analysis indicates that the other two seasons (Belg and Kiremt) are becoming wetter. The rainfall in Kiremt is increasing significantly (significant at the $p=0.05$ level) in Debre Tabor station with a rate of $10.20 \mathrm{~mm} /$ year. Besides, $78.1 \%$ of the total annual rainfall in the basin occurs during this rainy (Kiremt) season, whereas Bega and Belg contribute some $9.4 \%$ and $12.5 \%$, respectively. Furthermore, the correlation analysis of rainfall and SSTs indicates that rainfall of the LTB is highly affected by the variations of SSTs.
\end{abstract}

\section{Introduction}

The impacts of climate change and climate variability on human life have led the scientific community to monitor the behavior of weather and climate variables. Rainfall as one of the most important of these variables has a direct and indirect impact on the natural environment and human life. A large spatial and temporal variability of rainfall leads to an increased incidence of extreme events such as floods and droughts. It is also recognized that rainfall is one of the key climatic variables that affect both the spatial and temporal patterns on water availability [1]. Moreover, erratic rainfall can trigger various disasters, for example, floods, landslides, water logging, erosion, and salinity intrusion [2]. Every minor change in the rainfall intensity or amount imposes a severe challenge on the rural people since their main livelihood depends on agriculture which mostly relies on a short rainy season.

Various studies have indicated changes in the spatial and temporal variability and trends of rainfall pattern due to climate change and climate variability at different spatial (e.g., regional and national) and temporal (e.g., annual, seasonal, and monthly) scales in Ethiopia. For example, a study by Worku [3] indicates that flooding is a familiar event in the upper Blue Nile basin and did cause a lot of destruction in the past years. Bewket and Conway [4] have discussed about the decline of annual rainfall in the northwestern parts of Ethiopia, while there was no clear trend of annual rainfall in other parts during their observation time. Osman and Sauerborn [5] also determined that 

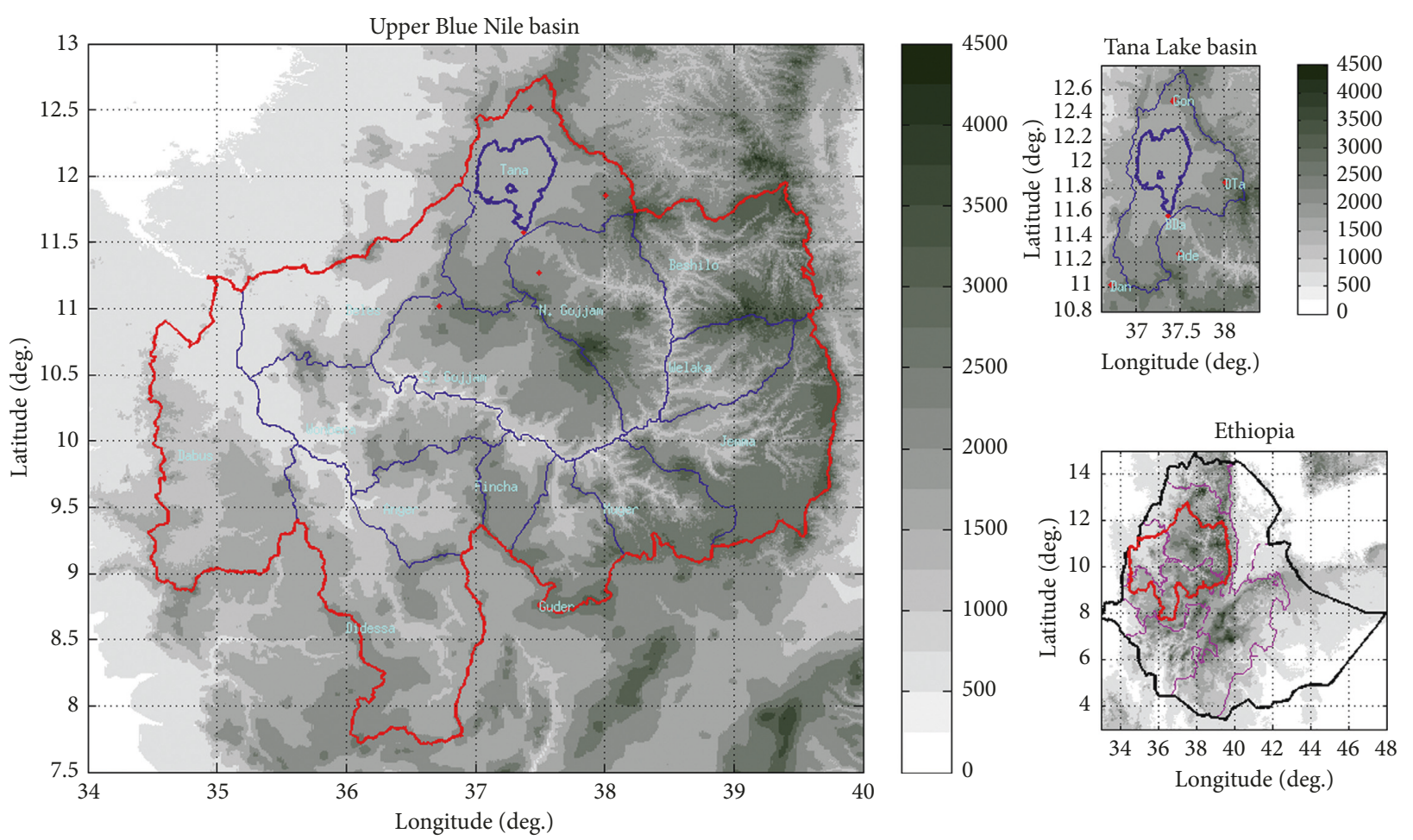

FIgURE 1: Study area and location of the meteorological stations (red points) used in the study.

summer rainfall, locally called Kiremt rainfall, in the central highlands of Ethiopia declined in the second half of the 20th century. Therefore, monitoring and quantifying the background trends of rainfall in the country as a whole and its sections is of vital importance.

Hydrologic time series almost always exhibit seasonality due to the periodicity nature of the weather. In Ethiopia, this arises greatly from seasonal variations in the precipitation volume, as well as in the rate of evapotranspiration. This variation can also be associated with the sea surface temperature (SST) dynamics. Previous studies mention that correct representation of ocean-atmosphere interaction is important for simulating certain aspects of climate such as the organization and propagation of intraseasonal variability $[6,7]$ and precipitation variability and its relationship with underlying sea surface temperatures [8-10]. Trends of surface temperature and rainfall over Ethiopia may be affected by global ocean-atmosphere coupling [11]. However, the analysis of rainfall trends is important in studying the impacts of climate change and variability on water resource planning and management [12]; it has been recognized that global or continental scale observations of historical climate are less useful for local or regional scale planning [13-15].

Despite many papers have been documented on rainfall trends and variability, their analysis is limited to the main rainy season (June to September) and large spatial scales in Ethiopia; there are also very limited works done on the other seasons and around the LTB, and most researches lack to relate the variability or trends to large-scale drivers like SST. The aim of this study is therefore to analyze the spatial and temporal trends of rainfall in the LTB and their association with the global SST variations. The study uses the
Mann-Kendall trend analysis, Sen's slope estimator, and correlation techniques. Although the Mann-Kendall test is suitable for cases where the trend may be assumed to be monotonic and thus no seasonal or other cycle is present in the data, the Sen's method uses a linear model to estimate the slope (magnitude) of the trend and the correlation coefficient is used to evaluate the relationship between rainfall and SST variations.

\section{Methodology}

2.1. The Study Area. The LTB (Figure 1) is geographically located in northwestern Ethiopia at latitude $10.95^{\circ}$ and $12.78^{\circ} \mathrm{N}$ and longitude $36.89^{\circ}$ and $38.25^{\circ} \mathrm{E}$, with a drainage area of about $15,000 \mathrm{~km}^{2}$ [16]. Lake Tana, the largest lake in Ethiopia and the third largest in the Nile basin, is located in this basin. This lake is the largest freshwater and oligotrophic high-altitude lake in the world [17]. It is shared by the four administrative zones called Awi, North Gondar, South Gondar, and West Gojjam. The climate of the area is largely controlled by the movement of the intertropical convergence zone (ITCZ) and tropical highland monsoon, which results in a single rainy Kiremt season between June and September. Rainfall (70-90\% of total annual rainfall) occurs in this season. The mean annual rainfall is about $1358.42 \mathrm{~mm}$, and the mean annual temperature is about $21^{\circ} \mathrm{C}$.

2.2. Data. This study uses rainfall data of five meteorological stations on a monthly basis for the 1979-2015 timescale, collected from the National Meteorology Agency of Ethiopia (NMA), Bahir Dar branch office. Specific locations and the period of the rainfall data record of the meteorological 
TABLE 1: Geographical description of the meteorological stations and rainfall data record period.

\begin{tabular}{lccccc}
\hline $\begin{array}{l}\text { General } \\
\text { location }\end{array}$ & $\begin{array}{c}\text { Station } \\
\text { name }\end{array}$ & Lat. & Long. & Alt. (m) & $\begin{array}{c}\text { Period of } \\
\text { record used }\end{array}$ \\
\hline \multirow{4}{*}{ Lake } & Adet & 11.27 & 37.49 & 2179 & $1979-2015$ \\
Tana basin & Bahir Dar & 11.57 & 37.36 & 1800 & $1979-2015$ \\
& Dangila & 11.25 & 36.84 & 2127 & $1979-2015$ \\
& Debre Tabor & 11.86 & 38.02 & 2706 & $1979-2015$ \\
Gondar & 12.60 & 37.45 & 1967 & $1979-2015$
\end{tabular}

Lat. $=$ latitude $\left({ }^{\circ}\right)$; Long. $=$ longitude $\left({ }^{\circ}\right)$; Alt. $=$ altitude.

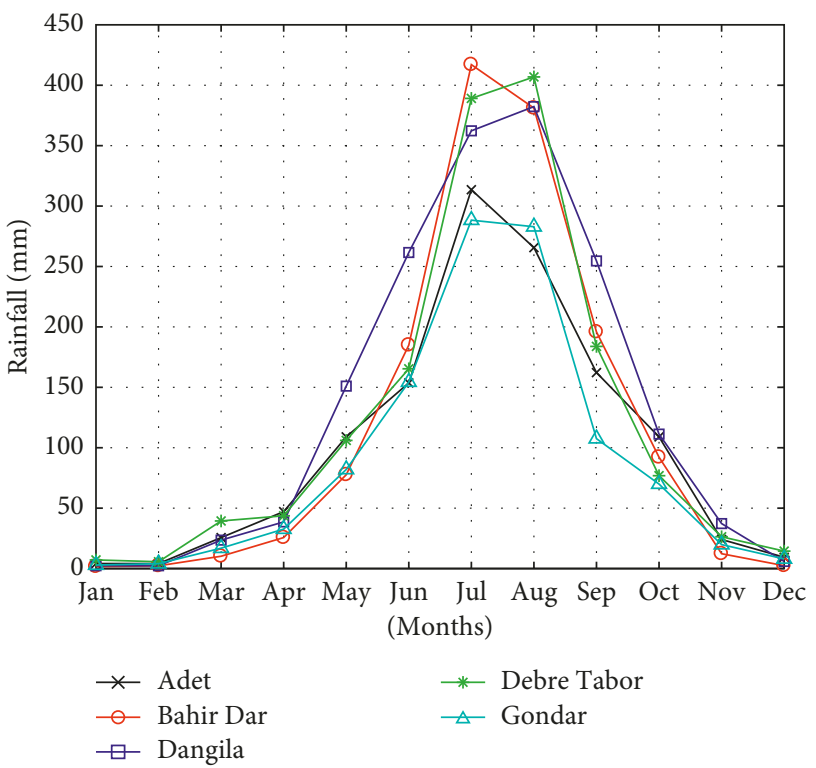

FIGURE 2: Mean monthly amount of rainfall for the selected stations averaged over the period 1979-2015.

stations are described in Figure 1 and Table 1, respectively. And the mean monthly rainfall of each station is illustrated in Figure 2. Station selection has been done based on quality, long-range data, and representation of various climatic zones in the study area. Additional criteria are, as suggested by Alexandersson in 1986 [18], the study of historical climate variability, and the change should utilize reliable data that are free of artificial trends or changes. Artifacts of the measurement caused by changes in the observation practice, equipment, site exposure, and location can led to misleading results when used in trend analyses [19]. Hence, the homogeneity test of the time-series rainfall data following some of the most reliable procedures recently proposed in the technical and scientific literature [20] has been applied in this study. The homogeneity test is an important issue to detect the variability of the data with time. We also utilize the SST data from the four observations of the National Oceanic and Atmospheric Administration (NOAA) COBE-SST version to relate the variations in the trend of rainfall with the global seasonal and annual SST dynamics [21]. Currently, the Earth System Research Laboratory, Physical Sciences Division (PSD), makes available these reanalysis data sets to the public in the standard netCDF file format at the following website: http://www.esrl.noaa.gov/psd/.
TABLE 2: Descriptive statistics of the annual rainfall for each station during 1979-2015.

\begin{tabular}{|c|c|c|c|c|c|}
\hline Rainfall & Adet & $\begin{array}{c}\text { Bahir } \\
\text { Dar }\end{array}$ & Dangila & $\begin{array}{l}\text { Debre } \\
\text { Tabor }\end{array}$ & Gondar \\
\hline Min. & 914.78 & 1076.50 & 1192.90 & 1096.70 & 843.8 \\
\hline Max. & 1685.10 & 1711.60 & 2008.60 & 1928.40 & 1258.7 \\
\hline Mean & 1227.23 & 1403.14 & 1633.01 & 1459.41 & 1069.36 \\
\hline $\begin{array}{l}\text { First } \\
\text { quartile }\end{array}$ & 1127.40 & 1251.50 & 1478.30 & 1281.80 & 990.30 \\
\hline Median & 1174.20 & 1418.20 & 1640.44 & 1493.70 & 1055.50 \\
\hline $\begin{array}{l}\text { Third } \\
\text { quartile }\end{array}$ & 1346.60 & 1508.70 & 1745.60 & 1579.70 & 1162.30 \\
\hline SD & 187 & 163.94 & 202 & 199.71 & 106.44 \\
\hline Variance & $35,050.60$ & $26,877.85$ & $40,928.16$ & $39,883.31$ & $11,328.67$ \\
\hline $\mathrm{CV}$ & 1.47 & 1.17 & 0.83 & 0.14 & 0.10 \\
\hline SE & 33.63 & 29.45 & 36.34 & 35.87 & 19.12 \\
\hline
\end{tabular}

$\mathrm{SD}=$ standard deviation; $\mathrm{CV}=$ coefficient of variance; $\mathrm{SE}=$ standard error.

In Ethiopia, there are three seasons with four months each, classified based on climatological means of rainfall and temperature. These seasons are locally known as Bega (October, November, December, and January), Belg (February, March, April, and May), and Kiremt (June, July, August, and September) $[22,23]$. In this study, we divided the time series of monthly rainfall data into three seasons and annual time-series categories as suggested by $[22,23]$.

2.3. Descriptive Statistics. In this study, we use these descriptive statistics to display information about the distribution of the rainfall data. These approaches are more precise and objective. The statistical descriptions of the annual rainfall of each meteorological station and seasonal rainfall of the Lake Tana basin are stated in Tables 2 and 3, respectively.

2.4. Mann-Kendall Trend Test. The Mann-Kendall (MK) test $[24,25]$, a nonparametric test method, has been widely used to detect whether trends exist in meteorological or hydrologic time series [26]. The Mann-Kendall trend test is also less sensitive to outliers, and it is the most robust and suitable for detecting trends in rainfall [27]. The nonparametric model Mann-Kendall test has been applied to the seasonal and the annual rainfall series to investigate the rainfall trends. For making statistical decision, the test statistics are evaluated at the 5\% $(p=0.05)$ level of significance.

The Mann-Kendall test statistic is denoted by $S$ and is computed using each pair of the observed values $x_{i}$ and $x_{j}$ of the random variable under consideration. Each pair is then inspected to find out whether $x_{i}>x_{j}$ or $x_{i}<x_{j}$. The Mann-Kendall statistic $S$ of the series $x$ is given by

$$
S=\sum_{i=1}^{n-1} \sum_{j=i+1}^{n} \operatorname{sgn}\left(x_{j}-x_{i}\right)
$$

where sgn is the signum function and $x_{i}$ and $x_{j}$ are the annual values in the years $i$ and $j, i>j$, respectively, and 
TABle 3: Descriptive statistics of the seasonal and annual rainfall in the LTB.

\begin{tabular}{|c|c|c|c|c|c|c|c|c|c|c|}
\hline Rainfall & Min. & Max. & Mean & First quartile & Median & Third quartile & $\mathrm{SD}$ & Variance & $\mathrm{CV}$ & SE \\
\hline Bega & 34.55 & 274.88 & 124.18 & 89.15 & 108.28 & 145.20 & 54.39 & 2958.05 & 0.44 & 8.94 \\
\hline Belg & 45.36 & 378.72 & 164.45 & 114.36 & 157.92 & 199.54 & 71.89 & 5167.72 & 0.44 & 11.82 \\
\hline Kiremt & 695.25 & 1365.01 & 1063.57 & 1022.59 & 1067.7 & 1106.93 & 114.59 & $13,131.72$ & 0.11 & 18.84 \\
\hline Annual & 1055.95 & 1640.12 & 1352.20 & 1287.54 & 1325.33 & 1411.14 & 120.20 & $14,448.19$ & 0.09 & 19.76 \\
\hline
\end{tabular}

$\mathrm{SD}=$ standard deviation; $\mathrm{CV}=$ coefficient of variance; $\mathrm{SE}=$ standard error.

$$
\operatorname{sgn}\left(x_{i}-x_{j}\right)= \begin{cases}1 & \text { if } x_{i}-x_{j}>0 \\ 0 & \text { if } x_{i}-x_{j}=0 \\ -1 & \text { if } x_{i}-x_{j}<0\end{cases}
$$

Under the null hypothesis of no trend, the statistic $S$ in (1) follows approximately normal distribution with mean zero and variance

$$
\sigma_{S}^{2}=\frac{n(n-1)(2 n+5)-\sum_{k=1}^{m} t_{k}\left(t_{k}-1\right)\left(2 t_{k}+5\right)}{18},
$$

where $m$ is the number of tied groups and $t_{k}$ is the number of data points in the group $k$.

When the sample size $n \geq 10$, as used in this study, the test statistic $Z$ is calculated from [25]

$$
Z= \begin{cases}\frac{S-1}{\sigma_{s}} & \text { if } S>0 \\ 0 & \text { if } S=0, \\ \frac{S+1}{\sigma_{s}} & \text { if } S<0\end{cases}
$$

The null hypothesis that there is no trend is rejected when the computed $Z$ value is greater than $Z_{\alpha / 2}$ in absolute value, where $Z_{\alpha / 2}$ is the smallest $Z$ which has the probability less than $\alpha / 2$ to appear in case of no trend. Accordingly, a positive value of $Z$ indicates an upward trend and a negative value of $Z$ indicates a downward trend. Finally, we explored the trend through time-series tables and plots of the rainfall data.

2.5. Sen's Slope Estimator. Sen's slope estimation [28] is another nonparametric method for trend analysis of the precipitation data set. It is used to detect the magnitude of the trend. The Sen's slope estimation is considered more robust than the least-squares method due to its relative insensitivity to extreme values and better performance even for normally distributed data [29]. In general, the slope $Q$ between any two values of a time series $x$ can be estimated from

$$
T_{i}=\frac{\left(x_{k}-x_{j}\right)}{j-k}, \quad j \neq k,
$$

where $x_{j}$ and $x_{k}$ are the data values for $j$ and $k$ times of a period $(j>k)$. The slope is estimated for each observation. For a time series $x$ having $n$ observations, there are a possible $N=n(n-1) / 2$ values of $T_{i}$ that can be calculated.
According to Sen's method, the overall estimator of the slope is the median of these $N$ values of $T_{i}$. The overall slope estimator $Q_{i}$ is thus

$$
Q_{i}= \begin{cases}T_{(N+1) / 2} & \text { for } N \text { odd observations, } \\ \frac{1}{2}\left(T_{N / 2}+T_{(N+1) / 2}\right) & \text { for } N \text { even observations. }\end{cases}
$$

When significant trends in the data were detected, 95\% confidence intervals were calculated using nonparametric techniques as described by Salmi et al. [30]. The positive or negative slope $Q_{i}$ is obtained as an upward (increasing) or downward (decreasing) trend.

The Mann-Kendall and Sen's tests were done by using MAKESENS, a Microsoft Excel template, which was developed by the Finnish Meteorological Department for detecting and estimating trends in the time series of the annual values of atmospheric and precipitation concentrations. MAKESENS is a widely used software for detecting and researching rainfall trends [31-34]. Detail information about MAKESENS can be obtained from the article written by Määttä et al. [35], and the website of the Finnish Meteorological Institute can be used to get more information on the MAKESENS application for trend calculation.

2.6. Correlation Coefficient. In this study, we use Pearson's correlation coefficient $(r)$ as defined by [36], with the significance assessed using the rainfall pattern of the LTB and the likelihood global sea surface temperature variations. A two-tailed, 5-percent significance level is adopted unless indicated otherwise. It should be mentioned that this significance test assumes normally distributed populations for both variables. The Pearson correlation coefficient $r$ in this research is defined as follows: Suppose that there are two variables $X$ and $Y$, each having $n$ values $X_{1}, X_{2}, \ldots, X_{n}$ and $Y_{1}, Y_{2}, \ldots, Y_{n}$, respectively. Let the mean of $X$ be $\bar{X}$ and the mean of $Y$ be $\bar{Y}$. Then, Pearson's $r$ is given by

$$
r=\frac{\sum\left(X_{i}-\bar{X}\right)\left(Y_{i}-\bar{Y}\right)}{\sqrt{\sum\left(X_{i}-\bar{X}\right)^{2} \sum\left(Y_{i}-\bar{Y}\right)^{2}}},
$$

where the summation proceeds across all $n$ possible values of $X$ and $Y$ in this sample.

By design, $r$ is described as $-1 \leq r \leq 1$. A correlation coefficient of approximately -1 indicates that as values of one variable increase, there is a perfectly predictable decrease in values of the other variables (in our case, SST and rainfall), and a correlation coefficient of approximately 1 indicates 


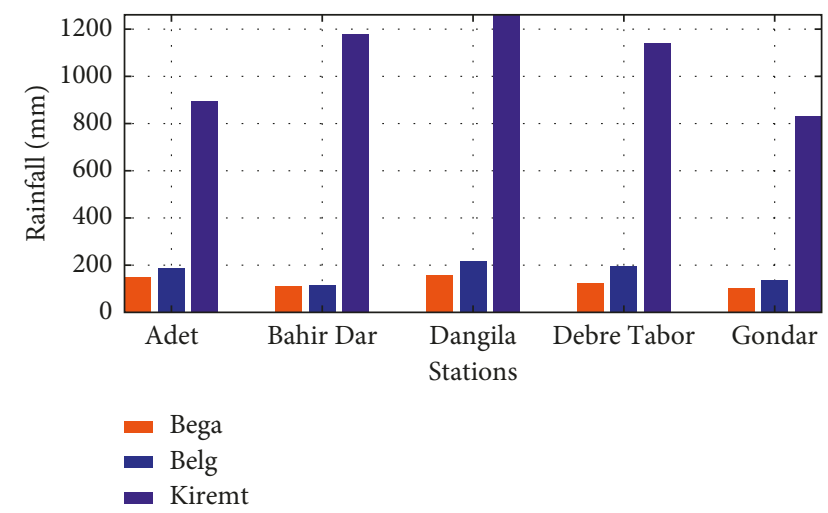

Figure 3: Mean seasonal amount of rainfall for each station from 1979 to 2015 .

that as values of one variable increase, there is a perfectly predictable increase in values of the other variables. However, a correlation coefficient of 0 indicates that as one variable changes (goes up or down), what happens to the other variables cannot be predicted.

\section{Results and Discussion}

\subsection{Station Basis Trend Analysis}

3.1.1. Seasonal Rainfall. The mean seasonal amounts of rainfall for the five stations in the LTB have been analyzed and summarized in Figure 3. The lowest amount of rainfall occurs during the Bega season, and the highest amount of rainfall occurs during the Kiremt season for all stations. The mean seasonal rainfall during Bega varies from 100.7 to $156.8 \mathrm{~mm}$. Rainfall gradually increases from the Bega season to the Belg season every year. During the Belg season, the mean rainfall varies from 115.8 to $215.5 \mathrm{~mm}$. The lowest amount of rainfall in this season occurs in Bahir Dar, and the highest amount of rainfall occurs in Dangila. After Belg, the rainfall increases sharply. The highest amount of rainfall occurs during Kiremt, and the amount of rainfall varies from 800 to $1200 \mathrm{~mm}$. During the Kiremt season, the maximum amount of rainfall occurs in Dangila (mean rainfall $1260.7 \mathrm{~mm}$ ) where its domination extends to the other seasons, and Bahir Dar and Debre Tabor receive a little more than $1100 \mathrm{~mm}$ of rainfall. Adet and Gondar receive the lowest amount of rainfall which is around $800 \mathrm{~mm}$. After Kiremt, rainfall decreases sharply to its lowest amount.

The trend statistics for the seasonal trend of rainfall (Table 4) show that there is an increasing trend during Kiremt in all meteorological stations except Adet. Kiremt rainfall is increasing in Bahir Dar, Dangila, Debre Tabor, and Gondar, and the rate (Sen's slope) of increase is $2.14,1.53$, 10.20 , and $3.18 \mathrm{~mm}$, respectively. The rate of decrease in Kiremt rainfall in Adet is $4.34 \mathrm{~mm}$. The increasing trend of Kiremt rainfall is statistically significant in Debra Tabor (bold values in Table 4). During Belg, rainfall shows an increasing trend in Dangila and Debre Tabor and a decreasing trend in Adet, Bahir Dar, and Gondar. On the contrary, Bega rainfall decreases in all stations except in Dangila which shows an increasing trend. The decreasing
TABLE 4: Seasonal rainfall trend and Sen's slope estimate for each station in the LTB, at a significance level of $\alpha=0.05$.

\begin{tabular}{lccccc}
\hline Station & Season & $\begin{array}{c}\text { MK test } \\
(Z \text {-test })\end{array}$ & Trend & Significance & $\begin{array}{c}\text { Sen's slope } \\
\text { (mm/year) }\end{array}$ \\
\hline \multirow{4}{*}{ Adet } & Kiremt & -1.12 & $\downarrow$ & Insig. & -4.34 \\
& Bega & -0.41 & $\downarrow$ & Insig. & -0.43 \\
& Belg & -1.02 & $\downarrow$ & Insig. & -2.13 \\
\hline \multirow{2}{*}{ Bahir } & Kiremt & 0.54 & $\uparrow$ & Insig. & 2.14 \\
Dar & Bega & -0.17 & $\downarrow$ & Insig. & -0.43 \\
& Belg & -0.10 & $\downarrow$ & Insig. & -2.13 \\
\hline \multirow{5}{*}{ Dangila } & Kiremt & 0.48 & $\uparrow$ & Insig. & 1.53 \\
& Bega & 0.44 & $\uparrow$ & Insig. & 0.74 \\
& Belg & 0.17 & $\uparrow$ & Insig. & 0.81 \\
\hline \multirow{2}{*}{ Debre } & Kiremt & $\mathbf{1 . 9 7}$ & $\uparrow$ & Sig. & $\mathbf{1 0 . 2 0}$ \\
Tabor & Bega & -0.10 & $\downarrow$ & Insig. & -0.08 \\
& Belg & 0.07 & $\uparrow$ & Insig. & 0.20 \\
\hline \multirow{2}{*}{ Gondar } & Kiremt & 1.46 & $\uparrow$ & Insig. & 3.18 \\
& Bega & -0.34 & $\downarrow$ & Insig. & -0.20 \\
& Belg & -0.31 & $\downarrow$ & Insig. & -0.41 \\
\hline
\end{tabular}

MK = Mann-Kendall; Insig. $=$ insignificant; Sig. $=$ significant; $\uparrow=$ upward; $\downarrow=$ downward.

TABLE 5: Mann-Kendall and Sen's test results of annual rainfall trends in the five stations at a significance level of $\alpha=0.05$.

\begin{tabular}{lcccc}
\hline Station & $\begin{array}{c}\text { MK test } \\
(Z \text {-test })\end{array}$ & Trend & Significance & $\begin{array}{c}\text { Sen's slope } \\
(\mathrm{mm} / \text { year })\end{array}$ \\
\hline Adet & -1.39 & $\downarrow$ & Insig. & -4.48 \\
Bahir Dar & 0.51 & $\uparrow$ & Insig. & 2.20 \\
Dangila & 0.78 & $\uparrow$ & Insig. & 3.42 \\
Debre Tabor & $\mathbf{1 . 7}$ & $\uparrow$ & Sig. & $\mathbf{6 . 5 8}$ \\
Gondar & 1.26 & $\uparrow$ & Insig. & 2.88 \\
\hline
\end{tabular}

MK = Mann-Kendall; Insig. = insignificant; Sig. = significant; $\uparrow=$ upward; $\downarrow=$ downward.

trend of Bega rainfall is statistically insignificant in Adet, Bahir Dar, Dangila, and Gondar; the rate of decrease is 0.43 , $0.43,0.08$, and $0.20 \mathrm{~mm}$, respectively. Generally, it can be noted that the trends of season rainfall for all stations during the study period (1979-2015) have been insignificant except for Kiremt in Debre Tabor.

3.1.2. Annual Rainfall. Trend analysis was also performed on an annual scale to examine whether there are trends in the data at this scale. The annual rainfall of the meteorological stations in the LTB varies by the location of the stations. Tables 2 and 5 show descriptive statistics and trend results of the annual rainfall for each station in the LTB, respectively. The annual rainfall during 1979-2015 varies from 843.8 to $2008.60 \mathrm{~mm}$ recorded at Gondar and Dangila, respectively (Table 2). Dangila which is situated in the southeastern part of the basin has received around 21\% higher annual rainfall than Gondar. During the analysis of the descriptive statistics, the standard deviation of the annual rainfall in all stations shows high values than the average values. This relation between the standard deviation and the average values indicates that the deviation from the normal distribution is considerable. This fact is especially 


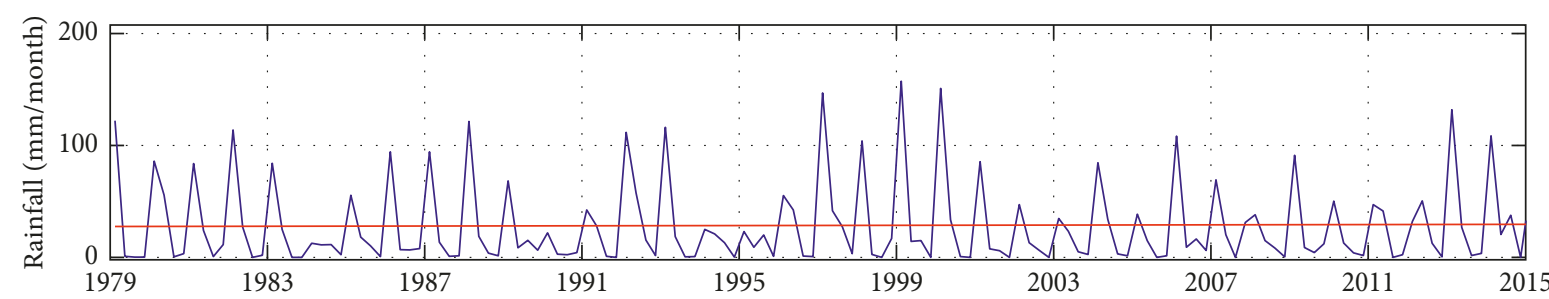

(a)

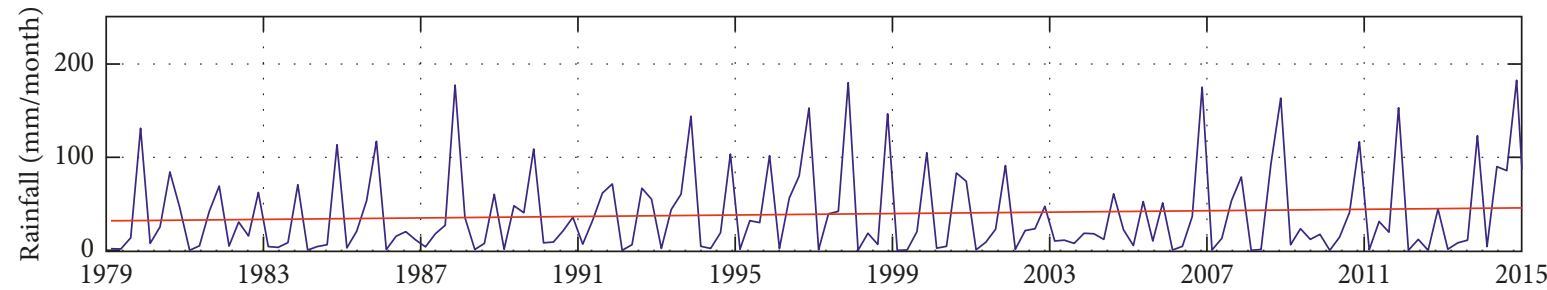

(b)

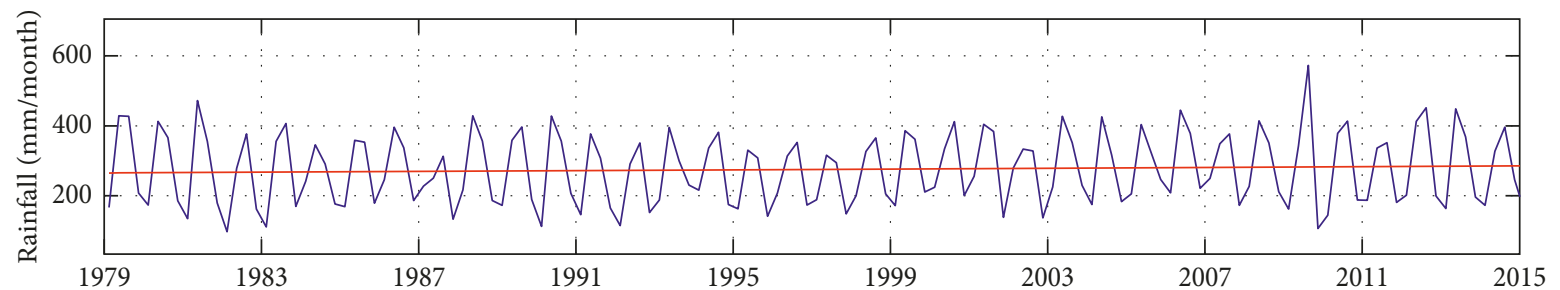

(c)

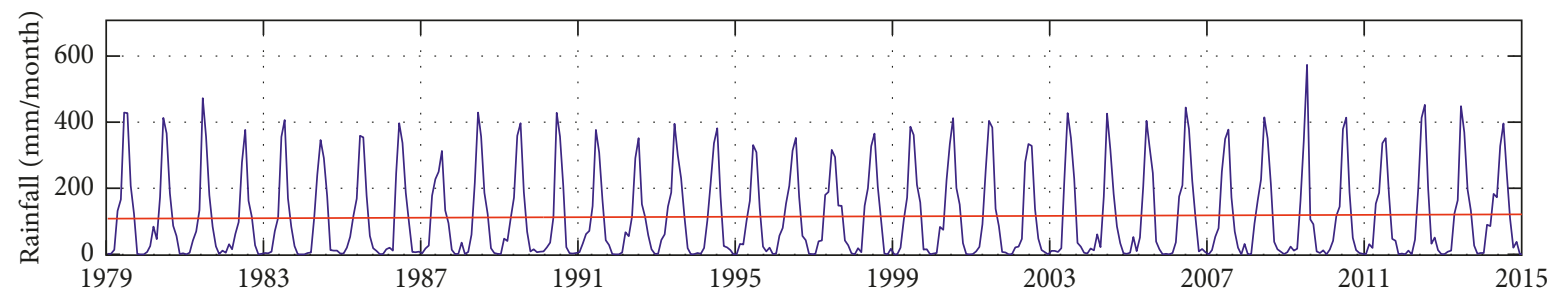

(d)

Figure 4: Rainfall trend of the Lake Tana basin at a significance level of 95\% confidence interval: (a) LTB rainfall trend (slope $=0.055)$ during Bega (ONDJ); (b) LTB rainfall trend (slope = 0.39) during Belg (FMAM); (c) LTB rainfall trend (slope = 0.56) during Kiremt (JJAS); (d) LTB rainfall trend (slope $=0.36$ ) for annual.

supported by the coefficients of variation of the annual rainfall which are over one or close to one. These show that, in mountainous areas, the rainfall values are much different from the average. Furthermore, it can be noted that the fact that the CV values (Table 2) are so high is an indication of the rainfall being highly variable and not dependable or reliable or can be attributed to the length of the data set being used or the quality of data. On the contrary, the lower the coefficient of variation of the rainfall amount in any year, the lower the variability and the greater the dependability. Coefficient of variation values less than 0.5 show lower variability from the mean. The amount of annual rainfall shows high variability from station to station and time to time.

The results of the Mann-Kendall trend test show an increasing trend in annual rainfall in four (Bahir Dar, Dangila, Debre Tabor, and Gondar) out of the five meteorological stations and a decreasing trend of annual rainfall in Adet. The annual rainfall in Debre Tabor is increasing significantly. And Sen's slope estimate rate of increase in annual rainfall in Bahir Dar, Dangila, Debre Tabor, and Gondar is $2.20,3.42,6.58$, and $2.88 \mathrm{~mm}$ per year, respectively, whereas the rate of decrease in annual rainfall in Adet is $-4.48 \mathrm{~mm} /$ year (Table 5). In general, rainfall in Adet shows distinct characteristics than that in the other stations. This could be associated with the geographical location of Adet, which is somewhat away from the other stations in the LTB (Figure 1). The increase in annual rainfall of the four stations is due to the rainfall received in Kiremt (main rainy seasons).

3.2. Regional Trend Analysis. In addition to the trend analysis of rainfall at the station level, we examined the regional-level trends by averaging the rainfall of all stations in the study area. Although the climate change affects resources in a cumulative manner, it is useful to determine whether certain seasons are more susceptible. Table 3 presents the descriptive statistics of the seasonal rainfall in the Lake Tana basin for the period of 1979-2015 and 

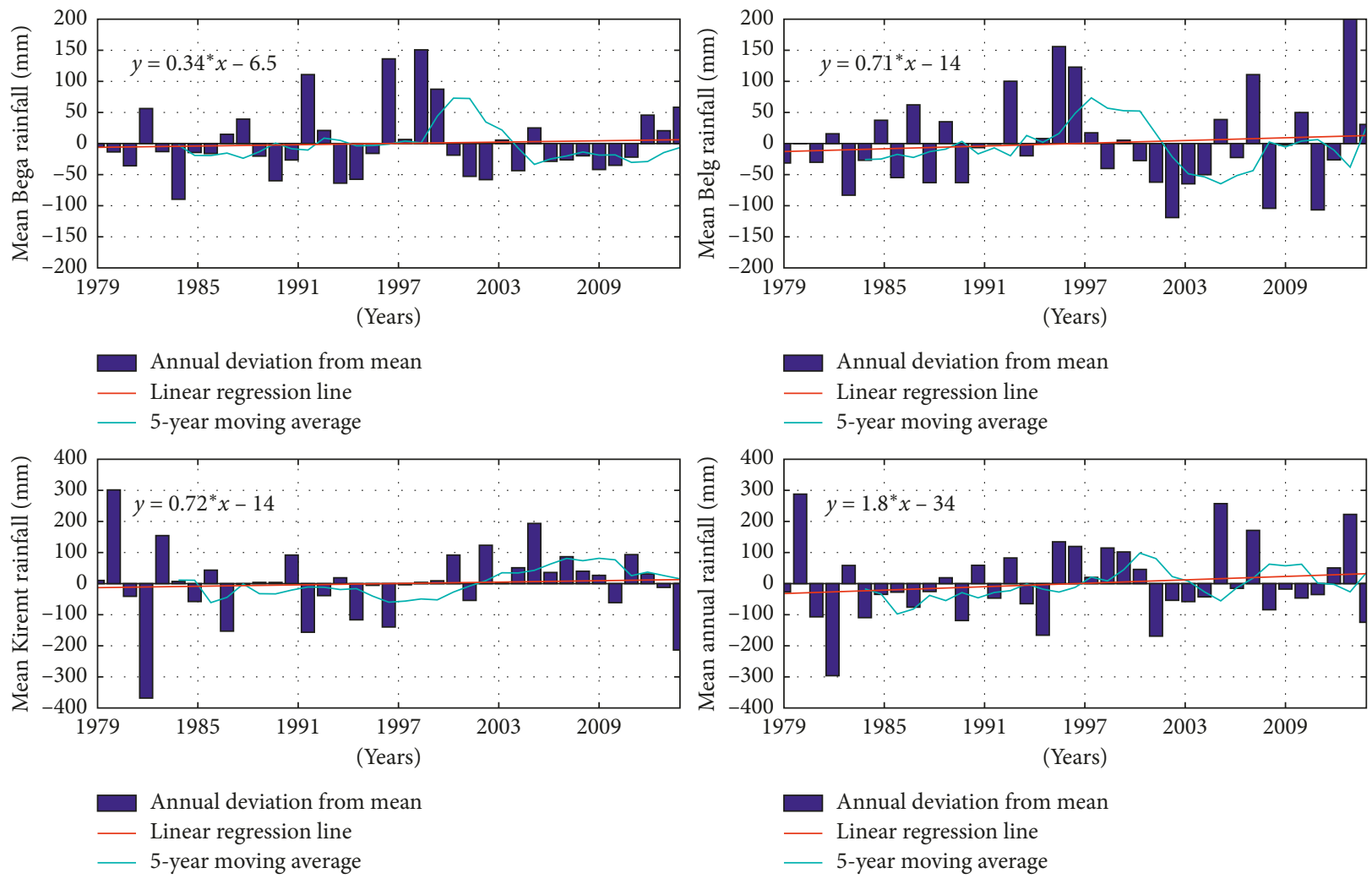

Figure 5: Mean seasonal and annual rainfall and equivalent linear regression trend line and 5-year moving average line plotted for the different aggregated station data sets. (a) Bega. (b) Belg. (c) Kiremt. (d) Annual.

seasonal contribution to the annual rainfall. The mean seasonal rainfall is $124.18 \mathrm{~mm}, 164.45 \mathrm{~mm}$, and $1063.57 \mathrm{~mm}$ for Bega, Belg, and Kiremt, respectively. Similarly, the mean annual rainfall is 1352.20 . Inspection of seasonal rainfall shows that $78.1 \%$ of the total annual rainfall in the basin is received during the Kiremt season. The Belg season receives the second highest amount of rainfall next to Kiremt. $12.5 \%$ of the total annual rainfall occurs during the Belg season. The lowest amount of rainfall occurs during the Bega season, that is, $9.4 \%$ of the total annual rainfall.

Previous studies confirm the similar statistical values of the seasonal rainfall around the LTB. For example, Setegn et al. [37] have indicated that $70-90 \%$ of total rainfall in the LTB occurs during the Kiremt season between June and September. The availability of high rainfall during the Kiremt season is part of a larger East African monsoon season spurred on by the shifting of the intertropical convergence zone (ITCZ) northward [38, 39]. Consequently, Bega is the driest season in the LTB and Kiremt is the wettest.

The standard deviation and coefficient of variance are high in the seasonal rainfall relative to the average values (Table 3). The coefficient of variance for Bega and Belg is $44 \%$, indicating that the Bega and Belg rainfall in the LTB is highly variable. However, the Kiremt and annual rainfall coefficient of variation values are $11 \%$ and $9 \%$, indicating less variability. Cherkos [40] summarizes that the coefficient of variation values $<20 \%$ indicate less variability, between $20 \%$ and $30 \%$ indicate moderate variability, and $>30 \%$ indicate high variability.
The regional rainfall trend (Figure 4) reveals an increasing trend in both seasonal and annual timescales. But the rate of increase is still insignificant as it is indicated by Sen's slopes. The rate of increase for Bega, Belg, and Kiremt rainfall was $0.055,0.39$, and $0.56 \mathrm{~mm}$. Similarly, annual rainfall was increased by $0.36 \mathrm{~mm}$ during $1979-2015$. Rainfalls in the study period have been rather highly variable (Figure 5). Previous studies near the Lake Tana basin and other parts of Ethiopia have also found insignificant trends at different spatial and temporal scales. For example, from the trend analysis of 53 years' daily precipitation data in Debre Markos, Shang et al. [41] found that there is no increasing trend in the extreme precipitation in Debre Markos. Similarly, Wing et al. [42] studied the trends and spatial distribution of the annual and seasonal rainfall in different parts of Ethiopia using data from 134 stations of 13 watersheds during 1960 to 2002 and showed no significant changes in annual watershed rainfall for any of the watersheds examined, except that a significant decline in Kiremt rainfall was recorded in watersheds located in the southwestern and central parts of Ethiopia. A recent study of the trend by Addisu et al. [43] at the significance level of $\alpha=0.05$ using NCEP data around the Tana basin found statistically significant annual rainfall irregularities. Although the Kiremt rainfall shows an increasing rate of 0.56, still it is not significant unless it is influenced by the significant trend of seasonal and annual rainfall in Debre Tabor station.

Figure 5 illustrates fitting of the linear regression trend and 5-year moving average line to the seasonal and annual 


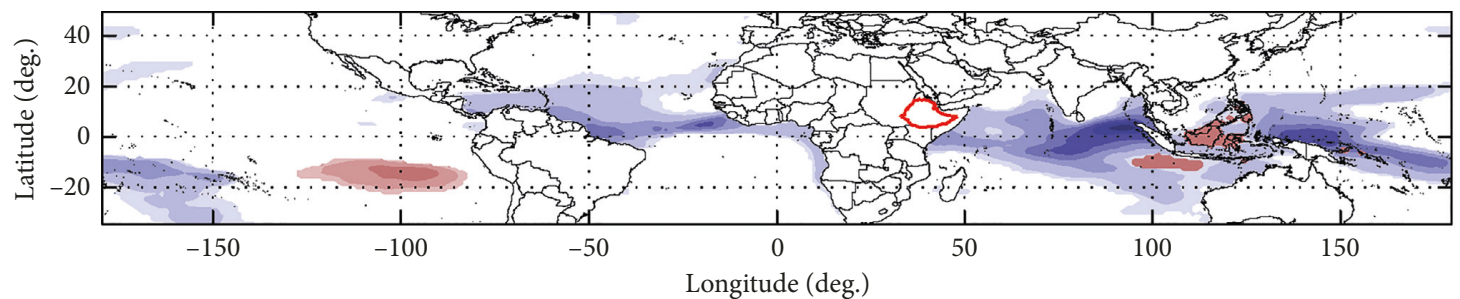

(a)

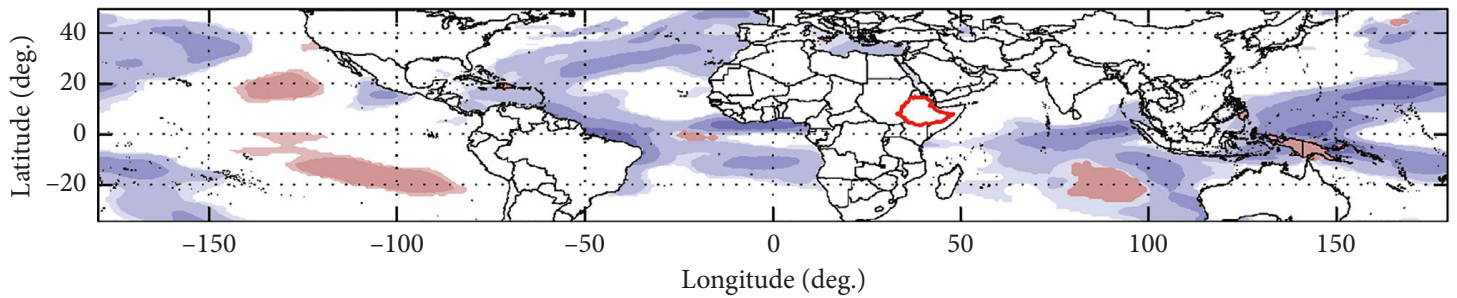

(b)

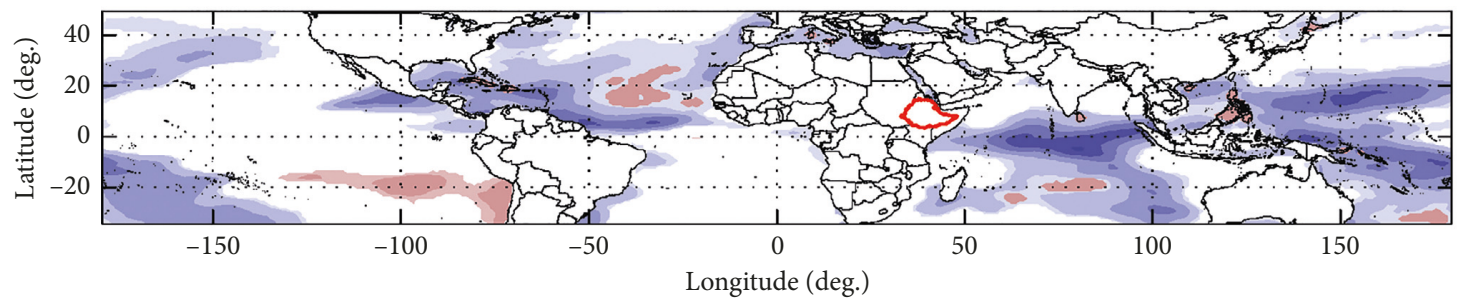

(c)

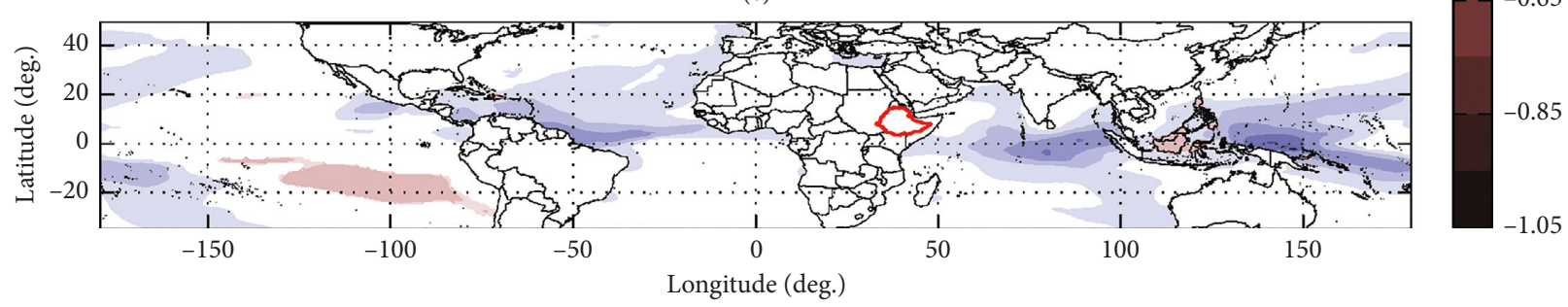

(d)

FIGURE 6: Rainfall and SST (averaged over 50 S-50 N, 200-200 E) correlations: (a) correlation coefficient of the Bega (ONDJ) rainfall trend and SST raw; (b) correlation coefficient of the Belg (FMAM) rainfall trend and SST raw; (c) correlation coefficient of the Kiremt (JJAS) rainfall trend and SST raw; (d) correlation coefficient of the annual rainfall trend and SST raw.

rainfall data series. The 5-year moving average line is a powerful trend indicator showing variations of the long study period in short bands. The seasonal and annual rainfall shows high interseasonal and interannual variability. This variability is tracked by the periodic fluctuations between consecutive wet years and consecutive dry years. The variation range of rainfall variability differs among different seasons. For instance, a recent weather variability of the year 2015 is remembered by the shortage of Kiremt rainfall in many parts of Ethiopia including the current study area; however, Bega and Belg seasons show a positive deviation from their long time averages (Figure 5). On the contrary, the linear regression trend confirms that there was no significance in the seasonal and annual rainfall trends during 1979-2015. It is worth witnessing that the Mann-Kendall trend test for the entire period was not statically significant.

3.3. Rainfall-SST Relationship. Previous studies have demonstrated that significant relationships exist on seasonal and intraseasonal timescales between precipitation and SST, shortwave flux, latent heat flux, and zonal momentum flux [8]. In this study, we focus on the relationship between seasonal and annual rainfall and SST by calculating correlations coefficients. Accordingly, the correlation coefficients show a positive relationship of rainfall with the SST variations particularly in the tropical region (Figure 6). Some parts of eastern Indian Ocean and Pacific Ocean also show negative correlation coefficients. This is associated with the variability in opposite modes of temperatures in the oceans such as El Niño-Southern Oscillation (ENSO) of the Pacific Ocean and Indian Ocean Dipole (IOD) of the Indian Ocean. These opposite SST anomalies provide varying rainfall as high and low to Ethiopia and the LTB in particular. A study in the upper Blue Nile basin by Seleshi and Camberlin [44] revealed that boreal summer rains correlation with ENSO has shown that warm ENSO periods (El Niño years) are typically associated with lower precipitation and drought years, while cold periods (La Niña years) are associated with higher precipitation quantities. The average fluctuation of the oceanic SST particularly the ENSO is between 3 and 7 years; the combined linear regression and 5-year moving 
average plot (Figure 5) confirms the fluctuations of rainfall between this period. Furthermore, the year 2015 (which was El Niño year) was considered as one of the warmest years in record and a dry year to Ethiopia; this is due to the failure of the Kiremt and annual rainfalls associated with the positive ENSO (El Niño) events.

\section{Conclusions}

The present study assessed the seasonal and annual trends of rainfall in the Lake Tana basin and their relationship with SST anomalies using time-series data from 1979 to 2015. Understanding of trends of rainfall would provide useful information for the planning, development, and management of water in any area or region. The hydrological response of any region depends on several climatic variables, particularly rainfall. The seasonal and annual trend of rainfall was analyzed at station and basin levels. The Mann-Kendall trend analysis confirms that there was no significant trend observed in all seasons. In addition, the linear regression trend analysis confirms the insignificant trend analyzed by the Mann-Kendall test. However, the seasonal and annual deviation and 5-year moving plots confirm that rainfall in the LTB was highly variable during the entire study period of 1979-2015. Generally, rainfall in Bega is decreasing in four out of five stations. This season receives the lowest amount of rainfall, that is, $128 \mathrm{~mm}$ per year. Hence, Bega is becoming drier. Although the annual rainfall in the Lake Tana basin is increasing, the rate of increase expressed by Sen's slope is still not statistically significant. The seasonal contribution to the total annual rainfall was $78.1 \%$ during the rainy (Kiremt) season and $12.5 \%$ and $9.4 \%$ during Belg and Bega seasons, respectively. Furthermore, the rainfall has been related to the SST drivers to examine whether the strong seasonal variability and annual variability are associated. From the rainfall-SST relationships, we conclude that the rainfall of the Lake Tana basin is affected by the SST variations.

Further studies are recommended to be conducted to investigate other rainfall characteristics at high (daily) temporal resolution such as extreme rainfall, dry days, rain days, and other climate change parameters for this region to confirm whether a significant trend exists, performing the proposed homogenization procedures and data quality analysis. And also local factors like topography and water bodies must be considered in addition to the global factors like SST.

\section{Conflicts of Interest}

The authors declare that there are no conflicts of interest regarding the publication of this paper.

\section{Acknowledgments}

The authors would like to express their sincere gratitude and appreciation to the Bahir Dar University for the funding support. Special thanks are due to the National Meteorology Agency of Ethiopia and all its members at the head office for providing the valuable data and support that made this study possible. The authors also thank all the reviewers for their important comments and suggestions.

\section{References}

[1] M. De Luis, J. Raventós, J. C. González-Hidalgo, J. R. Sánchez, and J. Cortina, "Spatial analysis of rainfall trends in the region of Valencia (east Spain)," International Journal of Climatology, vol. 20, no. 12, pp. 1451-1469, 2000.

[2] J. Matsumoto, "Synoptic features of heavy monsoon rainfall in 1987 related to the severe flood in Bangladesh," Bulletin of the Department of Geography, vol. 20, pp. 43-56, 1988.

[3] L. Y. Worku, "Climate change impact on variability of rainfall intensity in the upper blue Nile basin," Proceedings of the International Association of Hydrological Sciences, vol. 366, pp. 135-136, 2015.

[4] W. Bewket and D. Conway, "A note on the temporal and spatial variability of rainfall in the drought-prone Amhara region of Ethiopia," International Journal of Climatology, vol. 27, no. 11, pp. 1467-1477, 2007.

[5] M. Osman and P. Sauerborn, "A preliminary assessment of characteristics and long term variability of rainfall in Ethiopia-basis for sustainable land use and resource management," in Proceedings of the Challenges to Organic Farming and Sustainable Land Use in the Tropics and Subtropics, Deutscher Tropentag 2002, Witzenhausen, Germany, October 2002.

[6] M. Flatau, P. J. Flatau, P. Phoebus, and P. P. Niiler, "The feedback between equatorial convection and local radiative and evaporative process: the implication for intraseasonal oscillations," Journal of the Atmospheric Sciences, vol. 54, no. 19, pp. 2373-2386, 1997.

[7] K.-H. Seo, J.-K. E. Schemm, W. Wang, and A. Kumar, "The boreal summer intraseasonal oscillation simulated in the NCEP climate forecast system: the effect of sea surface temperature," Monthly Weather Review, vol. 135, no. 5, pp. 1807-1827, 2007.

[8] K. Pegion and B. P. Kirtman, "The impact of air-sea interactions on the simulation of tropical intraseasonal variability," Journal of Climate, vol. 21, no. 24, pp. 6616-6635, 2008.

[9] R. Wu, B. P. Kirtman, and K. Pegion, "Local rainfall-SST relationship on subseasonal time scales in satellite observations and CFS," Geophysical Research Letters, vol. 35, no. 22, 2008.

[10] M. Chen, W. Wang, A. Kumar, H. Wang, and B. Jha, "Ocean surface impacts on the seasonal precipitation over the tropical Indian Ocean," Journal of Climate, vol. 25, no. 10, pp. 3566-3582, 2012.

[11] M. R. Jury and C. Funk, "Climatic trends over Ethiopia: regional signals and drivers," International Journal of Climatology, vol. 33, no. 8, pp. 1924-1935, 2013.

[12] M. Haigh, "Sustainable management of headwater resources: the Nairobi 'Headwater' Declaration (2002) and beyond," Asian Journal of Water, Environment and Pollution, vol. 1, no. 1-2, pp. 17-28, 2004.

[13] J. Barsugli, C. Anderson, J. B. Smith, and J. M. Vogel, Options for Improving Climate Modeling to Assist Water Utility Planning for Climate Change. WhitePaper, Water Utility Climate Alliance, Clearwater, FL, USA, 2009.

[14] L. D. Brekke, J. E. Kiang, J. R. Olsen et al., Climate Change and Water Resources Management: A Federal Perspective, US Geological Survey Circular 1331, USGS Publications, Reston, VA, USA, 2009, http://pubs.usgs.gov/circ/1331/. 
[15] R. S. Raucher, The Future of Research on Climate Change Impacts on Water: A Workshop Focused on Adaption Strategies and Information Needs, WaterResearch Foundation, Denver, CO, USA, 2011, http://www.waterrf.org/projectsreports/publicreportlibrary/ 4340.pdf.

[16] MoWR, Bay River Basin Integrated Development Master Plan Project: 140, MoWR, New Delhi, India, 1998.

[17] CSA (Central Statistical Agency), Central Statistical Agency Population and Housing Census of Ethiopia, Central Statistical Agency, Addis Ababa, Ethiopia, 2007.

[18] H. Alexandersson, "A homogeneity test applied to precipitation data," Journal of Climatology, vol. 6, no. 6, pp. 661-675, 1986.

[19] T. R. Karl, P. D. Jones, R. W. Knight et al., "A new perspective on recent global warming: asymmetric trends of daily maximum and minimum temperature," Bulletin of the American Meteorological Society, vol. 74, no. 6, pp. 1007-1023, 1993.

[20] T. Szentimrey, "Multiple analysis of series for homogenization (MASH)," in Proceedings of the Second Seminar for homogenization of Surface Climatological Data, WMO, WCDMPNo. 41, pp. 27-64, Budaperst, Hungary, 1999.

[21] M. Ishii, A. Shouji, S. Sugimoto, and T. Matsumoto, "Objective analyses of sea-surface temperature and marine meteorological variables for the 20th century using ICOADS and the Kobe Collection," International Journal of Climatology, vol. 25, no. 7, pp. 865-879, 2005.

[22] W. Degefu, "Some aspects of meteorological drought in Ethiopia," in Drought and Hunger in Africa: Denying Famine a Future, M. H. Glantz, Ed., pp. 23-26, Cambridge University Press, Cambridge, UK, 1987.

[23] T. Gissila, E. Black, D. I. F. Grimes, and J. M. Slingo, "Seasonal forecasting of the Ethiopian summer rains," International Journal of Climatology, vol. 24, no. 11, pp. 1345-1358, 2004.

[24] H. B. Mann, "Nonparametric tests against trend," Econometrica, vol. 13, no. 3, pp. 245-259, 1945.

[25] M. G. Kendall, Rank Correlation Measures, Charles Griffin, London, UK, 1975.

[26] X. L. Wang, Q. H. Wen, and Y. Wu, "Penalized maximal t-test for detecting undocumented mean change in climate data series," Journal of Applied Meteorology and Climatology, vol. 46, no. 6, pp. 916-931, 2006.

[27] T. S. Keredin, M. Annisa, B. Surendra, and A. Solomon, "Long years comparative climate change trend analysis in terms of temperature, coastal Andhra Pradesh, India," Abhinav National Monthly Refereed Journal of Research in Science and Technology, vol. 2, no. 7, 2013.

[28] P. K. Sen, "Estimates of the regression coefficient based on Kendall's tau," Journal of the American Statistical Association, vol. 63, no. 324, pp. 1379-1389, 1968.

[29] R. M. Hirsch, J. R. Slack, and R. A. Smith, "Techniques of trend analysis for monthly water quality data," Water Resources Research, vol. 18, no. 1, pp. 107-121, 1982.

[30] T. Salmi, A. Maatta, P. Anttila, T. Ruoho-Airola, and T. Amnell, Detecting Trends of Annual Values of Atmospheric Pollutants by the Mann-Kendall Test and Sen's Slope Estimates-The Excel Template Application MAKESENS, Finnish Meteorological Institute, Helsinki, Finland, 2002.

[31] S. D. Río, L. Herrero, R. Fraile, and A. Penas, "Spatial distribution of recent rainfall trends in Spain (1961-2006)," International Journal of Climatology, vol. 31, no. 5, pp. 656667, 2011.

[32] N. R. Nasher, "Impact of climate variability on temperature and rainfall trend in Bangladesh: a case of two cities," European Journal of Climate Change, vol. 11, pp. 5-10, 2013.
[33] S. Nenwiinia and T. A. Kabandab, "Trends and variability assessment of rainfall in Vhembe South Africa," Journal of Human Ecology, vol. 42, no. 2, pp. 171-176, 2013.

[34] C. Tudose, A. Croitoru, and I. Haidu, "Some aspects on rainfall maximum intensity in North Western Romania," in Proceedings of the 13th SGEM Geo Conference on Energy and Clean Technologies, pp. 771-778, Bulgaria, June 2013.

[35] A. Määttä, T. Salmi, P. Anttila, and T. Ruoho-Airola, MAKESENS 1.0. Excel Template for the Calculation of Trend Statistics of Annual Time Series, Finnish Meteorological Institute, Helsinki, Finland, 2002.

[36] M. R. Spiegel, Theory and Problems of Statistics, Schaum's Outline Series, McGraw-Hill, New York, NY, USA, 5th edition, 1998.

[37] S. G. Setegn, R. Srinivasan, A. M. Melesse, and B. Dargahi, "SWAT model application and prediction uncertainty analysis in the Lake Tana Basin, Ethiopia," Hydrological Processes, vol. 24, no. 3, pp. 357-367, 2010.

[38] J. Griffiths, "Ethiopian highlands. Climates of Africa," in World Survey of Climatology, J. Griffiths, Ed., vol. 10, pp. 369-388, Elsevier, New York, NY, USA, 1972.

[39] D. Gamachu, Aspects of Climate and Water Budget in Ethiopia, Addis Ababa University Press, Addis Ababa, Ethiopia, 1977.

[40] A. Cherkos, The Rainfall Variability of an Area with Coefficient of Variation. CSA 2006/7 National Statistics, Central Statistical Agency, Addis Ababa, Ethiopia, 2001.

[41] H. Shang, J. Yan, M. Gebremichael, and S. M. Ayalew, "Trend analysis of extreme precipitation in the Northwestern Highlands of Ethiopia with a case study of Debre Markos," Hydrology and Earth System Sciences, vol. 15, no. 6, pp. 1937-1944, 2011.

[42] H. Wing, B. Gabriel, and A. Singha, "Trends and spatial distribution of annual and seasonal rainfall in Ethiopia," International Journal of Climatology, vol. 28, no. 13, pp. 1723-1734, 2008.

[43] S. Addisu, Y. G. Selassie, G. Fissha, and B. Gedif, "Time series trend analysis of temperature and rainfall in lake Tana Sub-basin, Ethiopia," Environmental Systems Research, vol. 4, p. 25, 2015.

[44] Y. Seleshi and P. Camberlin, "Recent changes in dry spell and extreme rainfall events in Ethiopia," Theoretical and Applied Climatology, vol. 83, no. 1-4, pp. 181-191, 2006. 

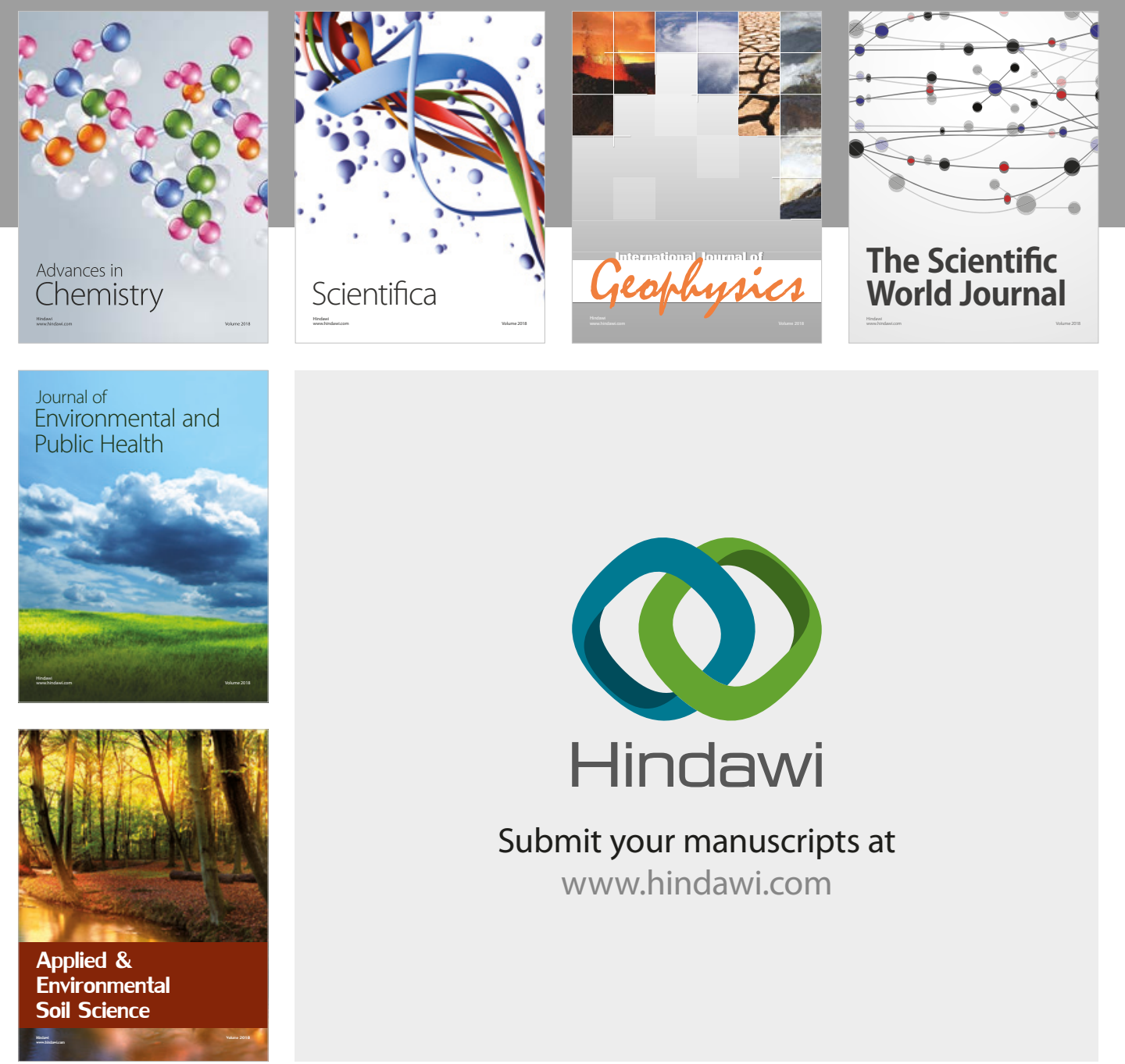

The Scientific

\section{World Journal}
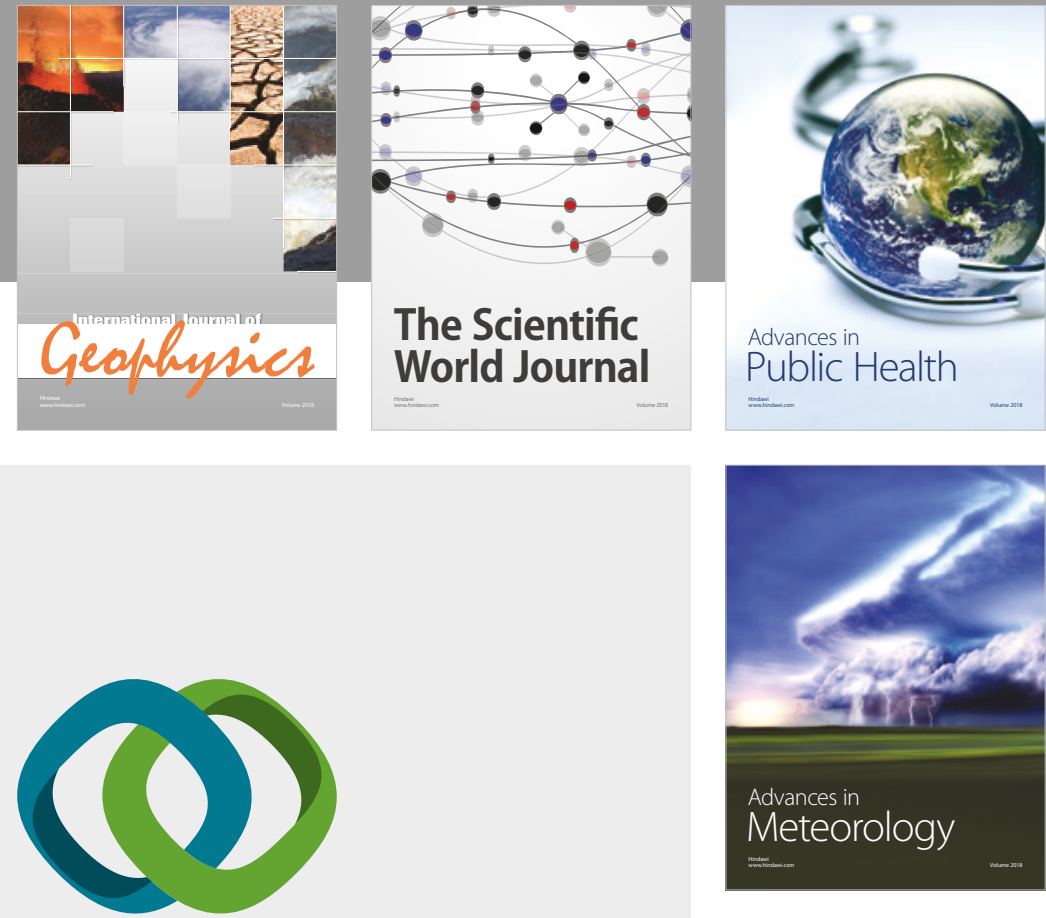

Advan

Public Health

\section{Hindawi}

Submit your manuscripts at

www.hindawi.com
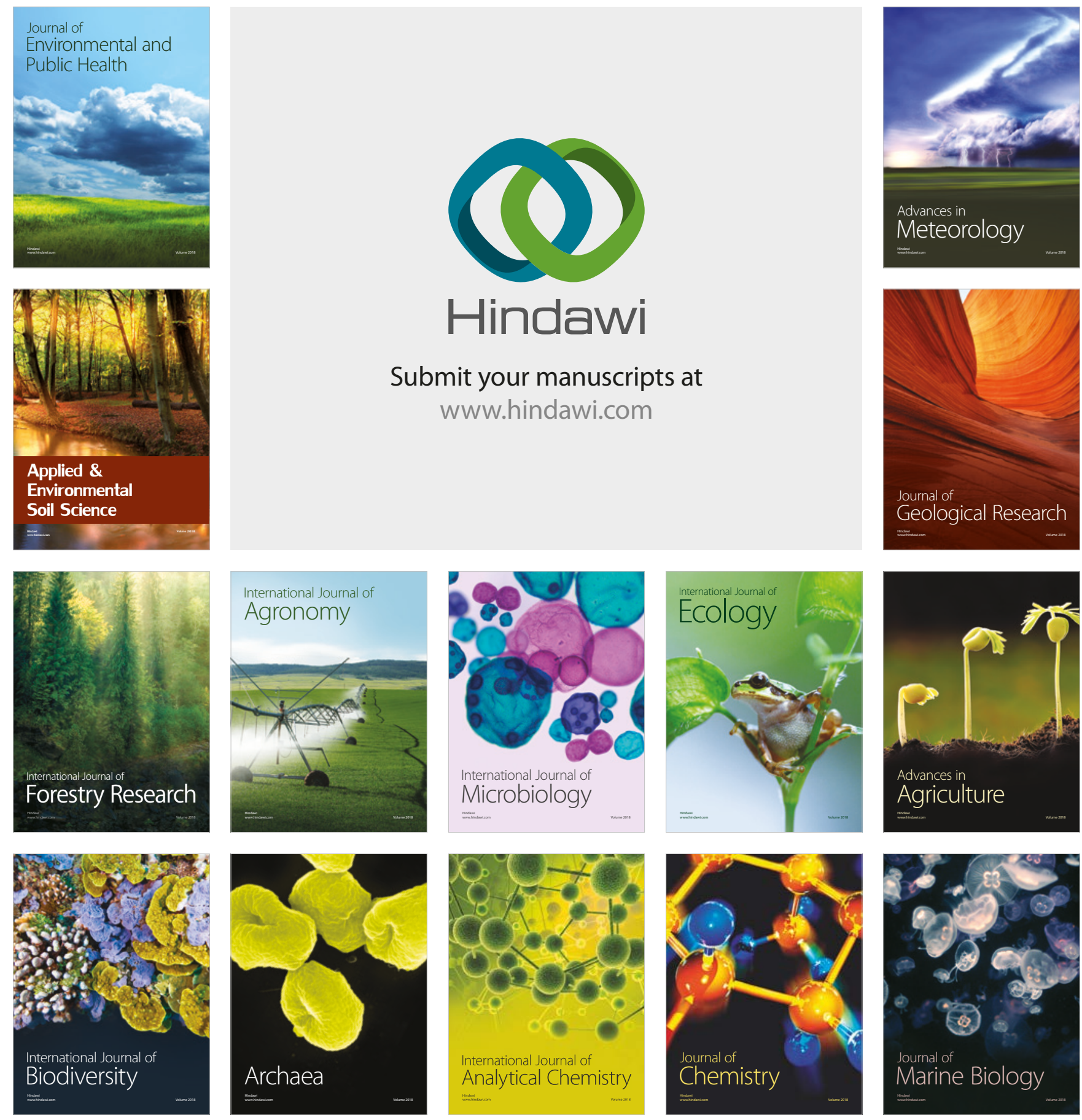